\title{
Ideological Dimension of the Network Society and the Ideology of Global Humanism
}

\author{
Anna Sergeevna Frolova \\ Southern Federal University, Rostov-on-Don, Russian Federation \\ Email: frannser@gmail.com \\ Yury Grigorievich Volkov
}

Southern Federal University, Rostov-on-Don, Russian Federation

Doi:10.5901/mjss.2015.v6n3s3p39

\begin{abstract}
The article analyses the ideological dimension of formation of the network society. A new era has set the new global challenges to the humanity. The revolution in information and communication technologies led to the transformation of the society and its processes. We can say that the network society offers a radically new view of the world and metaphoric of thinking. A new type of a human being and of what the ideology of the network society will be, its value system depends on what kind of a human being will be formed - a one-dimensional or multidimensional kind. The paper shows that network society itself is an ideological construct and carries the criticism, in the first place, on the ideas of neoliberalism. Ideology in the network society plays a key role, as it becomes a matrix of deciphering symbols, allowing network elements for using the same network code, without which network processes flow and network self-organizing are impossible. However, at this moment, the ideology of the network society is not yet fully formed. The concept of the network society, the principle of network and network processes are widely used in the ideological confrontation on the world stage when the network "hands down" the necessary ideological constructs. The article shows that the best ideological project that meets the needs of the network society on imagination, creativity and innovation, as well as able to ensure the preservation of spirituality, humanity and the priority of self-identity is the ideology of global humanism.
\end{abstract}

Keywords: network society, network processes, ideology, ideological dimension, the ideology of humanism.

\section{Introduction}

One of the main global trends in the late XX - early XXI century is the rapid development of information and communication technologies, which led to the emergence of a new type of society, differing with the social structure and the nature of social interactions as well as the transformation of power relations. One of the leading theorists of the network society, M. Castells, writes that the radically new social structure of the network society, in which stage the biggest part of the planet comes, is based on the new economy. "This economy is capitalist, but it is a new form of capitalism, informational and global. In other words, knowledge and information have become the key sources of productivity and competitiveness" (Castells, 2000). In this case, the generation of new knowledge, retransmitting and decryption of information depend on access to appropriate technology infrastructure, as well as on the quality of human resources, i.e. ability to manage information systems.

Networks are open structures that can expand indefinitely to include new elements or nodes. The network is built, and functions, if the elements of the network are able to communicate. This is only possible if they use similar communication codes (for example, values, or production problems).

The main characteristics of the social structure, which has a network base, include high dynamism and openness to innovation, without the risk of losing balance. The morphology of the network acts as a source of far-reaching restructuring of power relations. Information channels act as tools of the exercise of power, a kind of "circuit breakers" for network management. Active development and penetration into all spheres of the society of information technology has created a new material basis for the implementation of the control over the network elements permeating the entire social structure. 


\section{Relevant Scholarship}

Research in the field of the network theory and network processes rely primarily on American developments. For the first time, the network concept as applied to the targets the society of a potential enemy was developed by A.K. Cebrowski (Cebrowski et al, 1998). The studies of Western theorists, first of all, consider the impact of the network as an information and communication support of conflicts, including the provision of effective cooperation between military objectives, soldiers, software enabling to coordinate interactively actions, communications, etc. (Alberts, Stein, \& Garstka, 2000; Cebrowski, Navy, \& Garstka, 1998; Rubel, 2004; Hutchinson, 2006; Mitchell, 2009). However, the appeal to the category of network and network processes led to the formation of a new metaphoric of scientific and philosophical thought. The theories of network society started to be developed actively (Castells, 2000). The actor-network theory by B. Latour (Latour, 2007) is of particular interest.

Appeal to the category of the network raises a number of difficulties, since it requires access to the problem of information and communication, which is complex and poorly understood in the humanities and social sciences. The network is still primarily a technical phenomenon of new communication technologies. In this regard, Nazarchuk points to the need of convergence of the humanities with the natural and technical sciences to understand the new realities. Scientists emphasize that without the concepts of computer science, it is impossible to understand the emergent properties of the new social processes. The very concept of the network society requires an entirely new approach to the study of social phenomena, which are located at the intersection of computer science and sociology. It is necessary to study the process of the emergence of a fundamentally new quality of social communication, which is rapidly transforming all social institutions and practices (Nazarchuk, 2008).

Among researchers, considering the problems of social networking and the specifics of their operation, determined by the geometric configuration and information oriented network, we can highlight the following: D. A. Gubanov, D. A. Novikov, A. G. Chkhartishvili, G. V. Gradoselskaya, and V. M. Sazonov et al. The works by these researchers consider changing patterns of ruling and managing with the transition to network structures in society (Gubanov et al., 2010). Moreover, they analyse the network technologies and network processes in society (Sazonov); consider the network dimension of the society in general and the impact of the network theory on the sociological science (Gradoselskaya, 2004).

The fact that the network structure changes occurring in the very essence of society's processes changes not only the speed of their occurrence, but their character, their perceptions, and, thus, changes the picture of social reality, poses the problem of finding new principles of organization, management, and governing. Network society challenges stereotypes of the economic and political system. Analysis of the institutional and economic transformation under the influence of the network society and network processes is carried out in the study by such scholars as, for example, Miller J., Stuart R. (Miller \& Stuart, 2005), Benkler Y. (Benkler, 2006).

However, at present, there is practically no works offering a comprehensive socio-philosophical understanding of the ideological dimension of the network society, analysing the transformation of the ideological view of the world in the network society, on the one hand, and on the other - studying the transformation of the role of ideology in the network society.

\section{Methodology}

The author uses the multiparadigmality approach, with greater emphasis on post-non-classical paradigm. Thus, the methodological basis includes the theory of self-organizing systems, the principles of synergy, and the network theory. Network is organized on the fractal principle. The network processes are seen as fluctuations in the network. In the context of this work, the network society is regarded as a non-linear, non-closed, unstable, dynamic self-organizing system.

The methodological basis of this work is to understand the network society as a network structure, a set of interconnected nodes and network elements. Inclusion in the network structure or exclusion of the relationships between networks, along with the configuration, "embodied using information technology, determines the configuration of the dominant processes and functions in our societies" (Castells, 2000). Networks are open structures that can expand indefinitely to include new elements or nodes. The network is built, and functions, if the elements of the network are able to communicate. This is only possible if they use similar communication codes (for example, values, or production problems).

The main feature of the network theory is that it is considering a wide range of structures. These include the structures of both micro- and macro-levels. According to this theory, the actors can be individuals, groups, organizations, 
and societies. In addition, if the actor-network theory is applied (Latour, 2006; Low. 2007), then the means and channels of communication, and modern information and communication technologies may be included as well.

\section{Conclusions and Discussions}

\subsection{Network and network society}

The network is self-organizing autopoietic chaotic system, which is self-reproducing and growing on fractal principle. According to the network theory, the actors in the network can be individuals, groups, organizations, societies, and even objects. Infrastructure, tools, and channels of communication play an important role for the network approach. It is not only the provision of a possibility for communication. A human being, being exposed to objects, also changes its view of the world and the response to external factors.

Objects also play a big role in the network, as often thanks to the latest information and communication technologies they can enter into a full two-way communication, sometimes even without the intervention and direct human control. An example can be the "artificial intelligence", a variety of intelligent, self-learning search engines in the Internet space, the bot-programs designed for both sending messages and for two-way communication (chat rooms, forums, messengers).

Let us have a look at the network society from the perspective of the actor-network approach proposed by B. Latour, and his concept of the "multiple spaces" and the "heterogeneous networks". In the works of Latour, objects have equal rights with the subjects. They, just like people, are "actants" - i.e., "involved in the action", which is extremely important due to the increasing role of information and communication technologies. This approach allows including means of communication, channels, software, etc. into the interactions network. The actor-network theory offers a radically new way of metaphoric for thinking about social matter - a metaphoric of networks and flows. This approach implies that the social matter shall be seen as inextricably linked, intertwined with the material, while the meaning matter with extended matter, and temporal matter - with spatial matter.

People and objects, writes B. Latour, are treated as nodes of a single hybrid network. The network is a collection of actants, interacting in the same space, and being aimed at solving of the general problem (Latour, 2007).

Unlike all other concepts, linking activities and intentionality, the actor-network theory considers the action as a change in the information field. Accordingly, the actor may be any information medium - a subject, a person, an institution, a scientific text, a computer software, etc. Information field in its essence does not have local topology, and the impact of actors at each other cannot be reduced to simple mechanical stress. Their effects may be mediated by any number of connections and links, at that, these links may be considered as actors.

The network is in constant motion. It is not static; it is changeable. Organization and reorganization of the network elements occurs continuously based on the principles of self-organization, and taking into account the wave effect when one change leads to the spread of the signal and, ultimately, to changes of many areas, if not of the entire network. A distinctive feature of autopoietic systems is that their product is themselves. At that, there is no clear differentiation of the producer and the product.

The advent of the Internet has led to move of autopoiesis to a new level. Perfect information systems of social networks in the Internet space lead to an exponential sophistication of complexity and transformation of the substrate of the communication interactions. In the process of continuous reproduction of own components, social networks not just build themselves, they extend own boundaries, redirecting, modifying, enhancing or reducing one or another act of communication users (Lavrenchuk, 2011).

Infrastructure, tools, and channels of communication play an important role for the network approach. It is not even the provision of a possibility for communication. A human being, being exposed to objects, also changes its view of the world and the response to external factors. The advent of mobile communications and the Internet accelerated the flow of virtually all processes in the society by several orders. The changes can be seen in the pace of life, the nature of the interaction with the information world, even in the worldview of a person, who is constantly situated in the information flow. The emphasis in the requirements for a human being shifted from the outside world. Now we have to be in a constant state of self-education, and knowledge sinks into the background, giving the way to the ability to find information and interact with it.

\subsection{Network society and ideology.}

The network principle implies decentration of social relations, which inevitably leads to the transformation of the 
established system of ruling and interaction, which in turn affects the entire ideological and value system of the modern society. Network society requires a revision of the existing ideological and philosophical orientations, as well as restructuring them into line with the new changing realities.

The network society is transforming not only the social structure and the character of the social interactions and processes. It is constructing a fundamentally new type of worldview and understanding of the world. The nature of human interaction with the environment is changing. Network processes create the new metaphoric of thinking.

The basis of interaction in the network structures is ongoing multilateral process based on the exchange of information from the network code pre-set by the identification system. The space for deployment of network relations can also be viewed as a social reality, which combines a variety of symbolic systems, and possess unique species of integration and sustainability. In fact, the network society is itself an ideological construct, based on hyper-liberalism, decentration, and hypertextuality. Network society generates the evolution of worldviews and value systems.

Ideological dimension of the network society cannot be ignored, since ideology creates a certain view of the world. Ideology is included in the individual process of cognition and interpretation of social reality, and, thereby, promotes the association and conceptualization of private and public spheres of life (Al-Dainee, 2012).

Ideology permeates the entire system of social relations and finds its direct expression through symbolic exchanges, which are, essentially, the invariant core of the whole system of social relations. At that, the symbolic exchange occurs mostly at the unconscious level, as common ideological attitudes determine patterns of interactions and reactions. Different symbolic systems such as mythology, religion, political discourse, according to the researchers, in fact, acquire a ritual character, form a human being's worldview, and will determine its behaviour and interaction in society using words and/or specific actions, having certain meaning.

Network approach brings a new perspective on society, creates a special logic of the network society, transforming the usual rational structure of the human psychology. Cognitive psychologists say that each person perceives themselves, the surrounding world, and other people through the prism of the formed cognitive system, i.e. "personal constructs". Developers of the network war theory suggest that today the transformations affect the deep level of human consciousness. A human being is not just creating some new scientific and technological achievements. The environment created by a human being also has a tremendous impact on the psyche of a human being, its mind, worldview, and inner peace.

Creating such a picture of the world, ideology sets the key to the interpretation of symbols. In this regard, we can talk about the formation of another ideology function in the network society - the function of the symbols interpretation matrix. Being a formalised and rationalised system of ideas and values, ideology puts certain kind of "filters" for the interpretation, passing through which the symbols acquire certain pre-set meanings in the minds pf the bearers. Ideology provides stereotypeness of such interpretations and, hence, of feedback reactions to the received signal.

In fact, setting the phenomena and interactions in society interpretation matrix, ideology becomes a universal system of self-description and self-awareness for the society.

Ideology is naturally embedded in the general philosophical and social discourse. Ideology is objectified in concrete social practices and is reflected in the decisions and reforms. Ideological constructs are translated into information space and reach certain network elements, which are just networked through a single ideology, giving a meaning to their activity. In accordance with the received signal and in case of need, network elements on the ground can start the processes of self-reconstruction, self-organisation, and implementation of the resulting message and/or transmitting of the converted signal further on the network. It is important to understand that the signals are propagated along the wave principle (if using the terminology of the natural sciences). It disparts from some frequency vibrations in all directions at the same time, completely penetrating the network.

In the ideological dimension of the network society, several levels can be identified. It is not yet fully formed, only receiving its shape ideology of the network society, based on a particular vision of the world and the metaphor of networks and flows. The ideology of the network society requires a revision of the existing ideas about the market, freedom, and democratic process. The researchers note that "digital democracy" has spawned new forms of civic engagement, differing with independence, dynamics, and changeability. Information and communication technologies provide the opportunity for new forms of social organization and social action. E-mail, blogs, online petition - all these have changed the nature of social activity, making it more dynamic and mobile. Public organizations lose a rigid hierarchy. They are in the transition to a decentralized state, which is immediately reorganized under a specific problem arising from the network.

In a network society, group activity is not based on institutional ties, but on self-organization. Groups are formed spontaneously through social networks, e-mail, online donations, and flash mobs. The ability to make connections and build interaction comes to the fore (Miller \& Stuart, 2005). 
Now, there is tension and struggle between the past, but still having the great power rigid hierarchical forms of organization and a fundamentally new network-centric way of thinking and organization. This leads to the creation of a special field of tension between the obsolescent institutional power relations and the "transactional" power, executed by billions of interactions (Miller \& Stuart, 2005).

The ideology of the network society has spawned a review and critique of the ideas of neoliberalism. The ideas of "neutrality" or "neutralonomics" are spreading and gaining influence. "Neutralism" is essentially a continuation of the ideas of hyper-liberalism. It comes from the fact that the information and the network must be public, not private property. It means that they shall not require payment for use.

Neutralists believe that the de-privatization of digital technologies will be a powerful impetus to the creation of a more equitable society. The freedom of the Internet space will create conditions for decentralized innovation. The freedom of the Internet from the dictatorship of the market will be the main basis of building democracy.

This means the review of approaches to intellectual property, the transition to "open-source" software to enable users for using, copying, distributing, and/or modifying the software freely. Neutralists argue that the Internet space and infrastructure, as well as all the information content shall be public property and be in the public domain to unleash the creative and innovative potential and encourage individual and collective activity (Miller \& Stuart, 2005).

All these can lead to a significant redistribution of wealth and power from the old organizational forms of business to certain groups of individuals and social groups, as well as business able to change continuously the shapes and patterns, able to use the tools and the benefits of the new social relations (Benkler, 2006).

The following ideological "cut" of the network society is the increase in the intensity of competition of ideas and ideological confrontation. Currently, there is no single global ideological project of the network society as such. The leading position in the ideological space is still occupied by the old ideological systems, the dominant of which is the neoliberalism. However, the principle of the network applies to the ongoing ideological confrontation. At that, ideologies are a tool in the global network confrontation. But here, it is crucial to distinguish between the "ideology-tool", which is probably not even an ideology, but certain ideological constructs profitable for the network, often taken out of the general ideological concept and "lined up" in such a way as to achieve the maximum effect, - and ideology, as the ideological basis of the network and society in general, setting a particular socio-cultural code to the existence and efficient operation of the network society (Frolova, 2013).

In this context, ideology acquires one more specific function of the symbols interpretation matrix. Ideology is a formalised and rationalised system of ideas and values. In a network society, it puts certain kind of "filters" for the interpretation, passing through which the symbols acquire certain pre-set meanings in the minds pf the bearers. Thus, ideology provides predictability and pre-set course of such interpretations and, hence, of feedback reactions to the received signal. Based on the ideological matrix, we differentiate dichotomy of friend or foe, enemy or ally, good or evil, right or wrong, etc., correlating each of the received signal with the existing system of values.

However, in today's globalised and information and communication based integrated world, the network society also opens up great opportunities for ideological confrontation. In fact, the so-called network wars, talks about which have become quite fashionable, are the materialisation of ideological confrontation. One can say that the state of a network war is an inherent characteristic of the network society; that network wars are fought constantly and in all directions simultaneously. In fact, it is a war of all against all. The objects appear both directly "enemies" and the so-called "neutral parties" (although there is no neutrality in a network war) and "friends" (a concept also becomes quite relative). The main form of network warfare is the implementation of so-called "effects-based operations" (Hutchinson, 2006; Dugin, 2009). In the theory of network warfare, effects-based operations means a set of actions aimed at creating a behaviour pattern for "allies", "neutral forces", and directly "enemies", both during the peace, and in the state of crisis and war. Network wars are fought simultaneously on all vectors in a multidimensional space - socio-cultural, cognitive, informational, and physical spheres. Often, several areas are impacted during the network wars. The epicentre of the network wars is the zone of intersection of these areas. This intersection forms a key area, in which the network effect is concentrates and the maximum possible effect is achieved.

\subsection{Global humanism and the network society.}

Recognizing the need and the paramount importance of human freedoms and, in particular, freedom of thought, it is undeniable that society is in need of the theory-designed integrating ideology. In this sense, the authors' appeal belongs to the view of ideology that defines it through its positive meaning, as a system of beliefs, aimed at a combination of public and private interests, and at formation of values and normative consensus in society (Volkov, 2014).

The ideological version of the world is a kind of social project. Ideology encompasses the pursuit of an ideal, 
building a better world based on fundamental ideas and understanding of the principles of the world order. Ideology performs the forecasting and planning functions for the social development strategies.

Network society cannot be limited by any borders. It strives for globality and integration. The ideology of the network society will also be global. However, what will be the basis of such an ideology? Now, during the period of making of the network society, it is necessary to grasp properly the emerging trends and to design an ideological project that meets all the challenges of the modern world and can claim to be global. The humanity stands at a crossroads; a fundamentally new type of a human being is being formed. Will it be one-dimensional, unspiritual, totally absorbed by technocentrism and consumer culture, having fragmented clipping thinking? Or will the humanity enter a new era? Will a truly multi-dimensional personality be formed, the core values of which will include self-improvement, continuous development, development of imagination and creativity, a constant process of creativity and creation?

In order to talk about the modern society, it is not enough to point to growing social uncertainty, the nebulous future prospects, social, and technological risks. An important characteristic is the emergence of new mass movements aimed at cultural and social changes that can be described as the movement of counter-identity acting outside the state, representing a challenge to the existing political regimes. Based on this, an idea emerges that the modern society features with revolutionary changes are committed not by the proletarian labour masses, but are becoming the lot of socalled creative class - the class incorporating social creative energy and applying for a new fair and balanced social reconstruction (Volkov, 2013).

Now, the most promising and meeting the requirements of the network society, its requests for imagination, creativity and innovation, is a humanistic project, which focuses primarily on the creative essence of a human being (Volkov, 2014) and the creation of a society of social humanism. Building a humanistic society requires a fundamental reorientation of the development of all the processes, structures, and areas of society.

A new type of people, forming in the network society, has undeniable advantages. On the one hand, this includes focus on creativity and innovation, pursuit of self-organization, focus on the positive interaction; on the other hand, these are the exemption from social expectations on absolute guardianship, understanding of the boundaries of responsibility of the state and society, the individual and the state.

The ideology of humanism differs from the traditional political ideologies that claim to be post-partisan, to have universality of cultural and social meanings and is full of anti-etatism pathos. One can reach this opinion if based on the demonstration of modern humanism options. It would seem that such a position saves humanity from the suspicion of imposing cultural hegemony and of the manipulation of consciousness. However, the desire to express a position, which is "above" the ideology, a position on humanistic freedom of choice and on the desirability of synthesis of ideology's humanistic elements can be interpreted as eclectic, leading to theoretical helplessness of humanity. It is important to understand that humanity cannot be understood and interpreted outside the ideological discourse, outside the interpretation of the cultural and social changes, outside the logic of the right. In other words, the sense of humanism is in accepting the status of ideology, recognising the value of a person as a socially active and creative individual.

According to I. Wallerstein: "We are faced with a stark choice: either "equal freedom"; or neither freedom nor equality; either real efforts to incorporate into society for each of us, or deeply divided world, a sort of universal apartheid system... The new world system will be primarily egalitarian (based on equality) and basically democratic" (Wallerstein, 2003, p. 136). Achieving such a world system, in which there will exist both freedom and equality, is possible only after the process of reorientation of the whole society on spiritual and creative development of a personality.

Wallerstein also says that the Universe demonstrates an evolutionary increase in complexity. The majority of the phenomena and processes cannot be explained based on the linearity and uniformity. Social systems are the most complex, being constantly in motion, development, and struggle to build a better society.

The network society is undoubtedly a complex society, and the principles of chaos theory apply to it. Such a society is not static; it is in constant motion and change. The ideology of the global humanism is the only way to ensure the preservation of a human person, to prevent its final "digitisation" and dissolution in the flows and networks. The ideology of humanism will create conditions for harmonious human existence in the network society, taking advantage of a new stage of human development for more effective and full disclosure of creative potential of a human being.

\section{References}

Alberts, D., Stein F., \& Garstka J. (2000). Network centric warfare: Developing and Leveraging Information Superiority. 2nd Edition (Revised). CCRP publication series.

Al-Dainee, M.A. (2012). Manipulative ideologies in modern Russia: political and psychological analysis: thesis research ...Candidate of Political Sciences. M. 
Benkler, Y. (2006). The Wealth of Networks. How Social Production Transforms Markets and Freedom. New Haven and London:Yale University Press..

Castells, M., Kiseleva E. (2000). Russia and the network society. The world of Russia. (p. 23-51). No. 1.

Cebrowski A., Navy U., \& Garstka J. (1998). Network-Centric Warfare: Its Origin and Future Proceedings. January 1998 Retrieved from: http://www.kinection.com/ncoic/ncw_origin_future.pdf

Cleland, S. (2009). Neutralism: Identifying the Commons Ideology behind Net Neutrality. February 2009. Retrieved from: NetCompetition.org

Dugin, A. (2009). The theoretical foundations network wars. Network wars: he threat of the new generation. M.: Publishing House "Yevraziiskoye dvizhenie".

Frolova, A.S. (2013). Network processes in the modern Russian society: ideological dimension. Socially-humanitarian knowledge. No. 7.

Gubanov, D. A., Novikov D. A., \& Chkhartishvili A.G. (2010) Social networks: models of informational influence, control, and confrontation. M.

Gradoselskaya, G.V. (2004). Network dimensions in sociology. M.

Sazonov, V.M. Socially-network technologies: System analysis and forecast. Digital resource. Retrieved from: http://v-school.ru/ $\mathrm{BQOK} / \mathrm{cct} . \mathrm{doc}$

Hutchinson, W. (2006). Information Warfare and Deception. Informing Science Volume 9. Retrieved from: http://inform.nu/Articles/Vol9/ v9p213-223Hutchinson64.pdf

Latour, B. (2007) On interobjectiveness. Sociological Review. No. 2.

Lavrenchuk, E. A. (2011) Autopoiesis of social networks in the Internet space: thesis research for the degree of the Candidate of Philosophical Sciences. M.

Low, J. (2006). Objects and space. Sociology of things . Ed. by V. Wachstein. M.

Miller, J. \& Stuart R. (2005). Network-Centric Thinking: The Internet's Challenge to Ego-Centric Institutions. Planetwork Journal.

Mitchell, P. (2009) Network Centric Warfare and Coalition Operations. New York: Routledge.

Nazarchuk, A. V. (2008). The network society and its philosophical understanding // Problems of Philosophy. No. 7. July.

Rubel, R. (2004). War-Gaming Network-Centric Warfare. Naval War College Review.

Volkov, Y.G. (2013) Creative class: the scope of social responsibility // Middle-East Journal of Scientific Research. Volume 15 Number (3). Retrieved from: http://www.idosi.org/mejsr/mejsr15(3)13/14.pdf

Volkov, Yu. G. (2014) Creative class - an alternative to political radicalism. Sociological studies. No. 7.

Volkov, Yu. G. (2014) Russian Society: state and prospects of the ideological sphere. Social and humanitarian knowledge. No. 2.

Wallerstein, I. (2003). The end of the familiar world: sociology of the XXI century. M.: Logos. 
ISSN 2039-2117 (online) ISSN 2039-9340 (print)
Mediterranean Journal of Social Sciences MCSER Publishing, Rome-Italy
Vol 6 No $3 \mathrm{~S} 3$ May 2015 